\title{
Práticas da cultura digital e inclusão: um relato de jovens em situação de vulnerabilidade social
}

\author{
Rosana Vieira de Souza \\ Sílvia Fighera de Medeiros
}

Práticas da cultura digital e inclusão: um relato de jovens em situação de vulnerabilidade social

Resumo: O presente artigo propõe uma reflexão sobre a apropriação da cultura digital por jovens em situação de vulnerabilidade social. Discute-se de que maneiras estes indivíduos vêm lidando com os desafios da chamada inclusão digital bem como a importância que a internet e os sites de redes sociais alcançaram no seu cotidiano. A partir de pesquisa qualitativa com entrevistas em profundidade junto a jovens em uma das regiões mais pobres da cidade de Porto Alegre, observou-se que o acesso às redes digitais não pressupõe o fim da divisão digital, mas constitui um passo fundamental em direção a uma maior equidade social.

Palavras-Chave: Cultura digital. Inclusão digital. Vulnerabilidade social.

Digital Culture Practices and Inclusion: Narratives of Young People in Situations of Social Vulnerability

Abstract: The present paper aims to analyze the appropriation of digital culture by young people in situations of social vulnerability. It discusses the ways in which these individuals have been coping with the challenges of digital inclusion, as well as the importance that Internet and social networking sites have achieved in their everyday lives. Based on a qualitative research with in-depth interviews with young people from one of the poorest areas in Porto Alegre city, the study concluded that having access to digital networks does not imply the end of digital divide, but it does constitutes a fundamental step towards a greater social equity.

Key-Words: Digital culture. Digital inclusion. Social vulnerability.

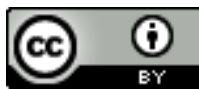

Esta obra foi licenciada sob uma Licença Creative Commons - Atribuição 3.0 Não Adaptada. 


\section{Introdução}

A digitalização da produção simbólica e cultural e a geração de uma economia baseada nos bens imateriais constituem mudanças que ajudaram a construir um novo contexto de possibilidades, onde o conhecimento é entendido como força produtiva primordial. O avanço em direção a um capitalismo informacional culturalmente diverso é atribuído às tecnologias de geração de conhecimento e processamento de informações (CASTELLS, 2002). A difusão das tecnologias da informação e da comunicação (TICs) foi expandida, em parte, em função da linguagem digital na qual a informação é gerada, armazenada, recuperada, processada e transmitida, como destacou Castells (2002) em sua concepção da sociedade da informação ${ }^{1}$.

Desta forma, modos diversos de produção e distribuição de energia, próprios do industrialismo, dão lugar ao paradigma sociotecnológico em que tais possibilidades, todas ligadas aos modos de acesso à informação, tornam-se fontes de produção e de poder, mudando a natureza do capitalismo e as formas de organização social (CASTELLS, 2011).

Neste contexto, não apenas o acesso ao aparato computacional, mas o domínio da gramática necessária para dar conta do contexto de conectividade, hipermobilidade e ubiquidade tecnológica (SANTAELLA, 2013), conduz a outros desafios para a questão dos limites já presentes entre os diversos estratos sociais. Em outras palavras, em tese, a apropriação social das tecnologias digitais contemporâneas (do acesso aos variados dispositivos conectados em rede às plataformas de redes sociais e serviços digitais) dependeria da presença de um conjunto de habilidades específicas do usuário para interagir com estas ferramentas que fornecem acesso à informação (CARDOSO, 2007).

Há, portanto, aparentemente, uma nova divisão de classes que não está ligada ao acúmulo de capital, mas às oportunidades de participação e acesso à informação oferecidas pelas redes eletrônicas. Teixeira (2010) chama esses novos limites de "divisão digital" e assim esta questão vem sendo objeto de discussão em vários campos de investigação (RONDELLI, 2003; HETKOWSKI, 2008; SILVEIRA, 2008; TEIXEIRA, 2010).

No contexto brasileiro, a reflexão sobre as exigências de uma cibercidadania (SILVEIRA, 2008) e a existência de uma divisão digital a partir do protagonismo crescente das TICs, encontra justificativa nos expressivos índices de desigualdade apresentados pelo país. Por outro lado, de acordo com dados do relatório anual da União Internacional de Telecomunicações (UNIÃO, 2013), a proporção de domicílios com computador no Brasil subiu de $45 \%$ para $50 \%$ no final de 2012 . O acesso à internet também subiu de $38 \%$ ara $45 \%$ em 2012.

A despeito deste crescimento, em parte, atribuído a esforços governamentais por meio do Plano Nacional de Banda Larga, o Brasil está em $62^{\circ}$ lugar no índice de desenvolvimento das TICs, integrando a categoria dos países menos conectados. O documento da UIT, amplamente reconhecido por governos e agências da Organização das Nações Unidades (ONU), classifica 157 países segundo seus níveis de acesso às

${ }^{1}$ Embora redutor no sentido de representar um recorte analítico que legitima o papel central das TICs na mudança social na contemporaneidade, considera-se que a ideia de sociedade da informação deve ser entendida no contexto das articulações que estabelece com a noção de economia da informação em rede, conceito desenvolvido por Benkler (2006). 
Tecnologias da Informação e Comunicação (TICs).

Diante desse cenário, o objetivo deste estudo foi analisar como se dá a apropriação da cultura digital pelos jovens que vivem em situação de vulnerabilidade social. Entender como funciona esse movimento é fundamental para a identificação de ações que podem ajudar a diminuir as diferenças sociais. Para tanto, foram realizadas entrevistas em profundidade com cinco jovens de 15 a 18 anos, moradores do bairro Mario Quintana, uma das regiões mais pobres localizada na cidade de Porto Alegre, Rio Grande do Sul. A pesquisa de natureza exploratória teve o intuito de captar as percepções destes jovens sobre as próprias práticas a partir das narrativas acerca do uso de dispositivos digitais e sites de redes sociais (SRS).

Em um primeiro momento, discute-se o conceito de inclusão digital e a importância alcançada pelas tecnologias da informação e da comunicação (TICs) na vida cotidiana dos indivíduos. Na sequência, insere-se o conceito de vulnerabilidade social e o contexto do estudo a partir do qual discutem-se os principais resultados das entrevistas em profundidade.

\section{Por que é preciso estar conectado?}

As Tecnologias da Informação e Comunicação (TICs) provocaram tantas mudanças que a sociedade contemporânea está se organizando, constantemente, por meio de complexas redes de relacionamento, motivadas pela disseminação e pelo compartilhamento de informações e conhecimentos. Segundo Teixeira (2010), esse papel de destaque é atribuído à valorização da informação, afirmando o conhecimento como matéria-prima e a tecnologia enquanto meio para agir sobre a informação.

Neste cenário, Schaff (1990, p. 50) já propunha que todas as esferas da vida pública estarão cobertas "por processos informatizados e por algum tipo de inteligência artificial". Nesse sentido, fala-se nas capacidades de instituições presentes na vida cotidiana dos indivíduos, tais como governos, hospitais, escolas, comércios, entre outros, para reunir e estruturar dados acerca dos indivíduos, seus comportamentos e crenças, transformando-os em informação para a tomada de decisão. A noção de divisão digital está relacionada à presunção de que o mundo se apresentará, de forma crescente, polarizado "entre aqueles que possuem informações pertinentes sobre diversas esferas da vida social e aqueles que estão privados destas" (SCHAFF , 1990, p. 51).

$\mathrm{Na}$ micro esfera cotidiana, pode-se especular o que perdem aqueles indivíduos para os quais a noção de uma "cultura digital" faz pouco sentido, quer em razão da não aderência às plataformas digitais, quer em função da participação apenas recente nas redes eletrônicas. Estar inserido nesses meios pressupõe a possiblidade de acesso a informações variadas não só sobre outras pessoas, mas sobre acontecimentos e agendas. Mas existem outras razões que devem ser consideradas para um grande contingente de novos entrantes na cultura digital.

A oportunidade que a internet apresenta - de resgatar a questão da coletividade é lembrada por Lévy (1999, p. 14), quando declara que as tecnologias da informação são, de fato,

Responsáveis por estender de uma ponta à outra do mundo as possibilidades de contato amigável, de transições contratuais, de transmissão do saber, de trocas de conhecimentos, de descoberta 
pacífica das diferenças, representando não apenas mais uma tecnologia da informação, mas um verdadeiro veículo de socialização.

Mais recentemente, de acordo com Castells (2013, p. 14), as pessoas criam significados "interagindo com seu ambiente natural e social, conectando suas redes neurais com as redes da natureza e com as redes sociais". E é por meio da comunicação que os seres humanos operam essas redes. Além disso, como destaca Teixeira (2010, p. 36),

É preciso reconhecer que, mais do que conectar equipamentos, conectam-se culturas e contextos diferenciados, ampliando as possibilidades de trocas e de crescimento sociocultural, mas também criando um novo território, aberto e indefinido, sujeito à manipulação de informações, à imposição cultural, à incitação para o consumo e a influências externas.

Nesse sentido, a possibilidade de realizar atividades em cooperação é uma das características mais significativas dessas redes. A internet, nesse aspecto, é extremamente eficiente, pois fornece meios de cooperação entre indivíduos e grupos, estimulando a troca de informações e a construção de conhecimentos em conjunto.

Para o Centro de Estudos sobre as Tecnologias da Informação e da Comunicação (CETIC.br) ${ }^{2}$, "as redes sociais propiciam o compartilhamento de ideias e valores entre pessoas e organizações que possuem interesses e objetivos em comum”. As redes sociais digitais constituem, assim, mecanismos de participação e mediação do diálogo social e político estabelecido em diferentes esferas da vida. Esse processo é baseado no reconhecimento do outro, conforme descreveu Lévy (1999, p. 30):

$\mathrm{Na}$ era do conhecimento, deixar de reconhecer o outro em sua inteligência é recusar-lhe sua verdadeira identidade social, é alimentar seu ressentimento e sua hostilidade, sua humilhação, a frustração de onde surge a violência. Em contrapartida, quando valorizamos o outro de acordo com o leque variado de seus saberes, permitimos que se identifique de um modo novo e positivo, contribuímos para mobilizálo, para desenvolver nele sentimentos de reconhecimento que facilitarão, consequentemente, a implicação subjetiva de outras pessoas em projetos coletivos.

De fato, por entender que o acesso à rede favorece a garantia de outros direitos (como econômicos, sociais, políticos e culturais), em 2011 a ONU declarou o acesso à internet como um direito universal. No ano seguinte, propôs que os países revisassem suas políticas de desenvolvimento dando status de infraestrutura básica para tecnologias de conexão como internet, telefones móveis e mensagens de texto.

Para Teixeira (2010, p. 40), é preciso pensar no conceito de inclusão digital de forma ampla, como processo horizontal:

[...] Que deve ocorrer a partir do interior dos grupos com vistas ao desenvolvimento da cultura de rede, numa perspectiva que considere

${ }^{2}$ O CETIC.br é um departamento do Núcleo de Informação e Coordenação do Ponto BR (NIC.br), que implementa as decisões e os projetos do Comitê Gestor da Internet do Brasil (CGI.br). 
processos de interação, de construção de identidade, de ampliação da cultura e de valorização da diversidade, para, desde uma postura de criação de conteúdos próprios e de exercício da cidadania, possibilitar a quebra do ciclo de produção, consumo e dependência tecnocultural.

A ampliação do conceito proposto por Teixeira vai ao encontro de uma experiência realizada em Nova Déli, na Índia, chamada O Buraco no Muro ${ }^{3}$. Em 1999, a empresa NIIT, liderado pelo então chefe de pesquisa e desenvolvimento humano da empresa, Sugata Mitra, conectou um computador à internet e o colocou no muro que separava a sede da entidade e a favela que ficava ao lado. A curiosidade das crianças as fez descobrir, em poucos minutos, como operar aquela máquina, embora nunca tivessem tido contato com um computador antes. Transpor a fronteira digital que se formava era o principal objetivo do experimento de Mitra. Segundo ele, O Buraco no Muro é uma porta através da qual muitas crianças podem chegar até a nova conjuntura.

A busca por essa transformação a que se refere Mitra também ocorre no Brasil. O Governo Federal, por exemplo, desenvolve o Programa Brasileiro de Inclusão Digital, e um de seus projetos mais conhecidos é o Cidadão Conectado - Computador para Todos (TEIXEIRA, 2010). Embora as mudanças sociais não sejam tão significativas quanto o que foi previsto com a criação das políticas públicas, a inclusão digital, enquanto caminho para o acesso à informação e ao conhecimento, busca colaborar para o desenvolvimento humano e social dos indivíduos. Questiona-se, a partir disso, como se desenvolve o binômio exclusão/inclusão digital no Brasil.

À medida que a cultura e a inclusão digital avançam no país, as populações mais jovens ganham destaque no novo cenário. De acordo com dados publicados pelo CETIC.br (2014), os usuários de internet de 10 a 15 anos de idade representam $67 \%$ do total, e entre os jovens de 16 a 24 anos, este número chega a $70 \%$.

Esses números, porém, não revelam o percentual específico por classes sociais, dados surpreendentes que o primeiro instituto de pesquisa no Brasil especializado em mercados emergentes, o Data Popular, mostrou ao país, em 2013 (MEIRELLES e ATHAYDE, 2014). Naquele ano, as classes C, D e E somavam cerca de 155 milhões de pessoas, contingente que consome tanto quanto a população de um país como a Holanda. A maior parte dessas pessoas, 11,7 milhões, é habitante das favelas brasileiras, território pouco explorado pelos pesquisadores.

Segundo Meirelles e Athayde (2014), as pessoas que moram nas favelas brasileiras se integram cada vez mais ao mundo das novas tecnologias da informação porque precisam trabalhar. O Google, por exemplo, é acessado por quem necessita pesquisar algo para a escola e também por aqueles que se preparam para concursos públicos. Computador e celular são importantes ferramentas de trabalho para autônomos e constituem, atualmente, para este público, porta de entrada para a inclusão digital.

Ao final de 2013, cerca de 50\% dos domicílios localizados em favelas contavam com conexão à internet, retirando das lan houses o papel protagonista que, inicialmente, desempenhavam no acesso às tecnologias da informação e da comunicação pelas comunidades mais carentes (MEIRELLES e ATHAYDE, 2014). Ainda, conforme Meirelles e Athayde (2014), cerca de $85 \%$ dos moradores destas regiões possuíam

${ }^{3}$ Disponível em: <https://www.youtube.com/watch?v=Xx8vCy9eloE $>$. Acesso em: 16 mar. 2015. 
telefone celular sendo $22 \%$ deles do tipo smartphones. Entre os jovens de 16 a 29 anos, $78 \%$ podiam ser considerados internautas e destes, cerca de $50 \%$ acessavam a rede pelo celular.

\section{Incluir para transformar: o contexto do estudo}

Mas o que caracteriza a situação de vulnerabilidade social? Para Abramovay et al (2002, p. 13), a vulnerabilidade social diz respeito a uma condição em que se verificam as consequências negativas "da relação entre a disponibilidade dos recursos materiais ou simbólicos dos atores, sejam eles indivíduos ou grupos, e o acesso à estrutura de oportunidades sociais, econômicas, culturais que provêm do Estado, do mercado e da sociedade".

De acordo com a Política Nacional de Assistência Social (PNAS), a perda ou a fragilidade de vínculos afetivos; a identidade estigmatizada em termos étnico, cultural e sexual; a desvantagem pessoal resultante de deficiências; a exclusão pela pobreza e/ou no acesso às demais políticas públicas; o uso de substâncias psicoativas; as diferentes formas de violência; a inserção precária ou a não inserção no mercado de trabalho formal e informal, e as estratégias e alternativas diferenciadas de sobrevivência, são alguns dos fatores que caracterizam a situação de vulnerabilidade social.

Esta é a situação de algumas das comunidades que, paradoxalmente, vivem em uma das regiões com os maiores índices de desenvolvimento humano do país - a região Sul. Com a renda per capita mais baixa por família, a região nordeste e o Eixo Baltazar, com população de aproximadamente 134 mil habitantes, é considerada a mais pobre da capital gaúcha, de acordo com dados do Atlas do Desenvolvimento Humano da Prefeitura de Porto Alegre (OBSERVA POA, 2014). Além das condições precárias de infraestrutura, segurança, habitação e saneamento básico, a região também apresenta um dos piores índices de desenvolvimento humano do município.

Ainda, segundo dados do Atlas, o percentual de crianças, adolescentes e jovens na região é de $37,92 \%$. A juventude é uma das principais preocupações das lideranças locais, porque as alternativas de desenvolvimento para essa faixa etária são insuficientes e/ou inexistentes.

Desde 1978, porém, alternativas vem sendo consolidadas no sentido de promover a inclusão de crianças e adolescentes em situação de vulnerabilidade social. Naquela época foi fundado, na cidade de Novo Hamburgo, Rio Grande do Sul, o primeiro Centro Social Marista (Cesmar), quando eram ofertadas aos educandos 4 oficinas de educação ambiental, jardinagem, artes visuais, esportes em geral, música, entre outras. Até 1999, as oficinas oferecidas desafiavam o comprometimento solidário e participativo, garantindo o crescimento da consciência autônoma e a busca pela profissionalização. Corte e costura, pintura, teclado, alfabetização de adultos, horta e grafite eram algumas dessas atividades.

A partir dos anos 2000, os educadores perceberam a necessidade de abrir espaço para as tecnologias: aulas de informática, o primeiro Centro de Recondicionamento de Computadores (CRC) da América Latina e o primeiro telecentro da região passaram a integrar o escopo de trabalho do Cesmar, iniciando a meta de inclusão digital nestas

\footnotetext{
${ }^{4}$ São chamados de educandos todos aqueles que são atendidos nos Centros Sociais Maristas. Os que frequentam as Escolas Sociais Maristas são chamados de estudantes.
} 
unidades. As iniciativas nasceram no bairro Mario Quintana, na capital, onde hoje está localizado o Cesmar e onde vivem os jovens que foram entrevistados para este artigo.

A maioria das Unidades Sociais Maristas está inserida em comunidades pobres, onde os índices de exclusão social, violência e drogadição sempre foram altos. Atualmente, a instituição atende crianças, adolescentes, jovens e adultos que vivem em situação de vulnerabilidade social, por meio de dezoito Centros e Escolas Sociais localizados em seis cidades do Rio Grande do Sul. Por meio das Políticas de Assistência Social e Educação, mais de 5 mil pessoas são atendidas diariamente nesses espaços, onde são oferecidas novas perspectivas de futuro e vida.

A região que circunda uma das unidades é formada por trabalhadores com baixa renda e rotina difícil. Na maioria das residências, são as mulheres que lideram as famílias, educando os filhos muitas vezes sem o apoio paterno. A história da unidade Marista se confunde com a do bairro nascido em 22 de dezembro de 1998 em homenagem ao poeta porto-alegrense (MENDONÇA, 2014). Sua origem remonta a época em que viviam moradores provenientes de desocupações do centro da cidade. Segundo Mendonça (2014, p. 31), "Sem infraestrutura, saneamento ou calçamento nas ruas, eram as botas de borracha que ajudavam educadores, educandos e colaboradores a fazer o difícil e enlameado caminho para chegar até o Cesmar...".

De acordo com MENDONÇA (2014, p. 49), os educadores vislumbram a criança e o adolescente "como um ser de direitos inserido em uma microestrutura comunitária e buscando se incluir em uma macroestrutura social extremamente excludente". Nesse contexto, a internet assume a função de apaziguar a desigualdade digital - e de proporcionar aos jovens, acima de tudo, o acesso ao conhecimento.

\section{A voz e o olhar dos jovens}

Este estudo, de natureza exploratória, buscou entender a relação de adolescentes em situação de vulnerabilidade social com tecnologias digitais e, em particular, com os sites de redes sociais (SRS), a partir da narrativa de cinco jovens, de 15 a 18 anos, que frequentam o Cesmar e são moradores do bairro Mario Quintana, em Porto Alegre. As entrevistas foram realizadas entre os meses de outubro e novembro de 2013, com duração média de 60 minutos. Para entender como se dá a apropriação da cultura digital por estes indivíduos, cuja renda familiar não permite "gastos excessivos e investimentos em coisas desnecessárias”, foi preciso conhecer não só a rotina deles enquanto estudantes e educandos, mas também enquanto filhos, irmãos e netos.

Os instrumentos de coleta de dados contaram com um primeiro bloco de questões gerais sobre a história de vida do entrevistado, situação familiar e relação com o Cesmar; o segundo bloco contemplou a relação do participante com as tecnologias digitais em geral, e com os SRS, em particular.

Benício $^{5}, 16$ anos, teve que esperar seu irmão mais velho se desfazer de seu celular para ter seu primeiro aparelho. A doação, pelo menos, veio com o pacote quase completo: era possível fazer ligações, mandar mensagens de texto e se conectar a redes wi-fi. Sua mãe ainda não permite que tenham internet móvel no celular, porque, segundo ela, as operadoras facilmente conseguem enganar os consumidores quando o

${ }^{5}$ Com o intuito de garantir o sigilo dos entrevistados deste estudo, este artigo utiliza nomes fictícios. 
assunto é internet ilimitada, e muitos acabam pagando mais do que devem - ou por falta de conhecimento, ou por "maldade dessas empresas".

A internet dentro de sua residência foi um sonho conquistado em 2012. Antes disso, Benício navegava na biblioteca do Cesmar. Foi ali que ele criou seu perfil no Facebook e no Twitter, em 2010. A segunda rede social do estudante, que está no $2^{\circ}$ ano do Ensino Médio, já foi "abandonada", mas a primeira se tornou sua principal fonte de informação.

Tenho que me esforçar para lembrar como era a vida antes do Facebook (risos). Só sei que eu chegava na sala de aula de manhã e não conseguia acompanhar todos os assuntos que os meus colegas falavam. Era nítido que, quem tinha internet em casa ou no celular, ficava sabendo de coisas antes de quem não tinha. Teve uma vez que um colega meu descobriu que a gente ia ter prova surpresa no dia seguinte. Ele postou no Facebook e a notícia se espalhou no nosso grupo de amigos. Adivinha o que aconteceu comigo? Só fiquei sabendo no dia seguinte, quase na hora da prova. Fui um dos últimos da minha sala a ter internet em casa (Benício, 16 anos).

Para Carla, 16 anos, por meio do Facebook ela consegue saber o que acontece em Porto Alegre, no Brasil e no mundo. Entretanto, dificilmente a educanda do Cesmar entra em sites de notícia, pois tudo o que ela precisa e gosta de saber acaba "aparecendo" em sua timeline do Facebook. Quando precisa fazer pesquisas e trabalhos para o colégio, utiliza o Google, mas, sempre que tem tempo, confere as informações em livros da biblioteca: "O lado ruim da internet não está escondido, pelo contrário, está bem na nossa frente. Tem muita mentira que é publicada, e quando eu fico desconfiada procuro a mesma coisa em diferentes lugares só para ter certeza".

Como é a mais velha de quatro irmãos, Carla sabe que deve dar exemplo dentro de casa e também nas redes sociais. Dois de seus irmãos já têm perfil no Facebook, por isso, ela mantém um perfil "discreto" para sua idade e, muitas vezes, faz questão de cuidar o que seus irmãos estão fazendo nas redes sociais. "Depois que eles entraram no Facebook, penso bastante antes de publicar alguma coisa. Acho que é muita exposição. Aqui na comunidade (eu moro aqui desde sempre!), todo mundo já sabe da vida um do outro, e agora com a internet ficou pior ainda".

Dos cinco jovens entrevistados, Amanda, 15 anos, foi a última a adquirir um celular com Android. Nos últimos meses, ela relata que viu a onda do aplicativo WhatsApp de longe, perdendo as principais "fofocas" da sala de aula e do grupo das melhores amigas: "Tinha dias que eu ficava no chat do Facebook direto, só pra não ficar por fora dos principais acontecimentos. Uma amiga minha que tinha Whats ficava me passando as 'informações' pelo chat (risos)". Amanda também utiliza o Google para fazer trabalhos do colégio. Está sempre na biblioteca do Cesmar, onde pode usar a internet à vontade, já que em casa ela tem que dividir o computador com outros três irmãos.

Rodrigo, 18 anos, sempre teve interesse em tecnologia, tanto que também é educando do Polo Marista de Formação Tecnológica, uma das três unidades que compõem o complexo Cesmar. Lá ele faz o curso Desenvolvimento de Projetos Tecnológicos (Deprotec), com conteúdos de eletrônica, software, comunicação, inglês, entre outros. Por esse motivo, foi o primeiro dos jovens entrevistados a ter um 
computador e, posteriormente, um notebook em casa. Morador do bairro Mario Quintana desde os 4 anos, Rodrigo se lembra quando o primeiro telecentro foi aberto no local: "Muitos vizinhos meus mexeram pela primeira vez em um computador aqui no Cesmar".

Por ser filho único (a exceção entre os cinco jovens) e estar envolvido com as tecnologias, o educando acredita que tenha sido mais fácil para seus pais aceitarem que o investimento no computador teria um retorno cultural, intelectual e social. De olho em seu futuro profissional, Rodrigo mantém seus perfis no Facebook e Instagram atualizados. Ele acredita que, atualmente, as empresas buscam profissionais analisando candidatos nos sites de redes sociais.

\begin{abstract}
Hoje eu tenho um celular que me permite estar conectado com o mundo o tempo todo. Meus pais também têm, só que o deles não tem internet móvel. Mas disso eu não abro mão, porque é nessa área que eu quero trabalhar. Tive que deixar de comprar outras coisas durante alguns meses, e não me arrependo. Comprei meu celular com o dinheiro que eu ganho dos meus pais todo mês - não é muito, mas eu consigo guardar - e com os trabalhos que eu faço às vezes como técnico de informática. Fiz em 12 vezes (risos) (Rodrigo, 18 anos).
\end{abstract}

Luiza, 16 anos, tem perfil no Facebook há dois anos e, desde então, mudou seu jeito de se comportar no mundo virtual, porque, segundo ela, "amadureceu na vida real". Para Luiza, não há diferença entre o mundo on-line e off-line, uma postura é reflexo da outra: "No início, eu adicionava todo mundo como amigo, mesmo não conhecendo a pessoa. Hoje, faço uma 'faxina' no meu perfil pelo menos uma vez por ano, e deleto até aqueles 'amigos' que não tenho mais contato". Segundo a educanda, números nem sempre significam qualidade: sua rede de amigos pode ser menor que a de outras pessoas com quem convive, mas Luiza garante que, dessa forma, mantém sua timeline interessante, com as notícias de quem (ou sobre o que) realmente importa para ela.

Quando o assunto é o compartilhamento de informações nas redes sociais, Luiza prefere não utilizá-lo com frequência: "Acho que quem compartilha muito é porque não tem muita coisa pra dizer, não tem foto legal pra postar, não tem o que fazer pra movimentar seu perfil. Eu prefiro postar coisas minhas, fotos, vídeos, textos, o que eu penso, a minha opinião sobre o que está acontecendo no mundo".

Às vezes tenho a impressão de que a galera perde a noção na internet. Mas, na verdade, a internet só expõe ainda mais essas pessoas, porque elas são assim fora das redes sociais também. Colocar uma foto e pedir curtida em troca de beijo é o fim da várzea. E tem também o SDV ("sigo de volta"), né. O Instagram está cheio disso. As pessoas ficam trocando seguidores, como se isso fosse deixá-las mais felizes. E o pior é que deve deixar mesmo! É muita carência (Luiza, 16 anos).

Quando perguntados sobre como ficam as pessoas que não têm acesso à internet, Benício, Carla, Amanda, Rodrigo e Luiza foram unânimes em suas respostas: esses indivíduos estão à margem da sociedade. Em suas palavras, e com base nas experiências que vivenciaram antes de ter um computador ou celular com internet, os jovens 
demonstraram que se sentiram excluídos socialmente por não ter determinadas informações ou ficar sabendo de acontecimentos depois da maioria das pessoas.

$\mathrm{Na}$ contemporaneidade, por mais que permaneçam conectados por meio de dispositivos digitais em rede, estes jovens percebem a diferença entre aqueles que têm acesso à internet móvel de forma ubíqua e aqueles que são dependentes das redes wi-fi disponíveis, eventualmente, de forma gratuita. Com exceção de Rodrigo, os outros quatro jovens relataram que, após a compra do celular com sistema operacional Android, passaram a frequentar locais que oferecem redes wi-fi gratuitas para poder se conectar. "A gente chega no lugar e antes mesmo de sentar já pergunta: 'Tem wi-fi?"”, comenta Benício, achando graça da situação.

Outro ponto de destaque na entrevista realizada com os jovens foi o papel da internet, especialmente do Facebook e Instagram, enquanto fonte de entretenimento. Todos eles mencionaram que se divertem consideravelmente quando estão lendo e vendo o que é postado nas redes sociais.

Para estes jovens que vivem nas comunidades, para se divertir, estudar e buscar uma vaga de emprego, é preciso estar conectado. A internet passou a constituir, também, uma espécie de válvula de escape para as dificuldades diárias enfrentadas por eles: "Tem muita coisa engraçada na internet. Eu sigo várias páginas e pessoas, como Felix Amargo e Hugo Gloss (...). É o momento do dia que eu tenho para dar risada, pensar besteira", relata Amanda.

Buscar maneiras para se conectar com o mundo passou a ser prioridade para essa geração, mesmo vivendo em condições que poderiam limitar o acesso à cultura digital. A economia que faziam ao longo dos meses passou a ter mais um objetivo: o investimento nas novas tecnologias. Em contrapartida, Benício e Carla também procuram curtir e seguir as páginas de políticos, como a da presidente Dilma Rousseff no Facebook, e dos principais meios de comunicação do país: "Leio só as chamadas das notícias. Se fico interessado, aí sim entro no site para ler a reportagem inteira, mas, geralmente, o que aparece ali já me basta", afirma Benício.

\section{Considerações finais}

É possível transpor o muro das barreiras digitais. A divisão de classes da sociedade contemporânea ganha novas proporções ao mesmo tempo em que é atenuada pela juventude. Os jovens que foram entrevistados para este artigo mostram como isso está acontecendo na prática. Mesmo pertencendo às classes mais inferiores de nosso sistema - e embora sejam moradores de um dos bairros com o menor índice de desenvolvimento humano de Porto Alegre -, esses jovens optaram por aproveitar as oportunidades de inclusão digital. Por meio dessas possibilidades, eles foram descobrindo o mundo virtual do conhecimento, do entretenimento e da empregabilidade - e estão invertendo a lógica de investimento e consumo de sua família. Os jovens são os principais disseminadores dos benefícios da cultura digital para a comunidade e sua própria família. É por meio deles que seus pais e avós se inserem nas redes sociais, enxergando as possibilidades de atividades econômicas e relacionamentos.

Segundo Castells (2013, p. 15), "para a sociedade em geral, a principal fonte da produção social de significado é o processo da comunicação socializada. O processo de construção de significado caracteriza-se por um grande volume de diversidade". Em 
meio às inúmeras portas que a internet abre aos indivíduos, os jovens se mostraram capazes de diferenciar o que os auxilia na construção do conhecimento e o que não acrescenta quando precisam pesquisar, estudar e compartilhar.

De acordo com Meirelles e Athayde (2014, p. 93), nas favelas "as pessoas integram-se cada vez mais ao mundo das novas tecnologias de informação. Pelo computador ou pelo celular, os trabalhadores autônomos podem receber recados e encomendas de seus clientes. Os desconectados perdem mercado rapidamente".

A inclusão digital que se vê vai ainda mais além. As redes sociais, a exemplo do Facebook, contribuem para a mobilização dos saberes, o reconhecimento das diferentes identidades e a articulação dos pensamentos que compõem a coletividade. A inclusão digital colabora significativamente para o desenvolvimento humano e social dos indivíduos, contribuindo para o processo de redução das diferenças sociais na sociedade da informação. Embora o maior acesso às redes per se - que se verifica neste estudo a partir da perspectiva dos entrevistados - não seja capaz de revelar as habilidades necessárias, no sentido discutido por Silveira (2008) para uma cibercidadania, considera-se que a participação destes indivíduos é um primeiro passo em direção à maior equidade social.

\section{Referências}

ABRAMOVAY, M.; CASTRO, G. M.; PINHEIRO, L. C.; LIMA, F. S.; MARTINELLI, C.C. Juventude, violência e vulnerabilidade social na América Latina: desafios para políticas públicas. Brasília: UNESCO, BID, 2002.

BENKLER, Yochai. The wealth of networks: how social production transforms markets and freedom. New Haven: Yale University Press, 2006.

CARDOSO, Gustavo. From mass to networked communication: communicational models and the informational society. International Journal of Communication, n. 2, p. 587-630, 2008.

CASTELLS, Manuel. A Era da informação: economia, sociedade e cultura. São Paulo: Paz e Terra, 1999.

CASTELLS, Manuel. A sociedade em rede. 6. ed. São Paulo: Paz e Terra, 2002.

CASTELLS, Manuel. A Network Theory of Power. International Journal of Communication, v. 5, p. 773-787, 2011.

CASTELLS, Manuel. Redes de indignação e esperança: movimentos sociais na era da internet. Rio de Janeiro: Zahar, 2013.

CETIC.br. Panorama Setorial da Internet. Redes sociais: revolução cultural na internet. Ano 2, n. 2, 2010.

CETIC.br. TIC Domicílios indica que $31 \%$ da população brasileira usa Internet pelo telefone cellular. Jun. 2014. Disponível em: 〈http://cetic.br/noticia/tic-domiciliosindica-que-31-da-populacao-brasileira-usa-internet-pelo-telefone-celular/>. Acesso em: 5 abr. 2015.

HETKOWSKI, Tânia Maria (Org.). Políticas públicas \& inclusão digital. Salvador: EDUFBA, 2008.

LÉVY, Pierre. A inteligência coletiva: por uma antropologia do ciberespaço. São Paulo: Editora Loyola, 1999.

MALINI, Fábio; ANTOUN, Henrique. @ internet e \#rua: ciberativismo e mobilização 
nas redes sociais. Porto Alegre: Editora Sulina, 2013.

MEIRELLES, Renato; ATHAYDE, Celso. Um país chamado favela: a maior pesquisa já feita sobre a favela brasileira. São Paulo: Editora Gente, 2014.

MENDONÇA, Rodrigo; SILVA, Mérli Leal (Org.). Centro Social Marista de Porto Alegre - Cesmar: 15 anos dedicados à transformação social. Porto Alegre: CMC, 2014. OBSERVA POA. Observatório da Cidade de Porto Alegre. Atlas do Desenvolvimento Humano. Disponível em: <http://www.observapoa.com.br/default.php?p_secao=44 >. Acesso em: 5 abr. 2015.

OST, Pedro. Caminhos de transformação: a trajetória social marista no Rio Grande do Sul. Porto Alegre: CMC, 2014.

RONDELLI, Elizabeth. Quatro passos para a inclusão digital. Sete Pontos, n. 5, Jul. 2003. Disponível em: <http://www.comunicacao.pro.br/setepontos/5/4passos.htm>. Acesso em: 16 mar. 2015.

SANTAELLA, Lucia. Comunicação ubíqua: repercussões na cultura e na educação. São Paulo: Paulus, 2013.

SCALCO, Lucia Mury. Máquinas, conexões e saberes: as práticas de inclusão digital em famílias de grupos populares. Tese (Doutorado) - Universidade Federal do Rio Grande do Sul, 2012.

SCHAFF, Adam. A sociedade informática: as consequências sociais da segunda revolução industrial. São Paulo: Uniesp Brasiliense, 1990.

SILVEIRA, Sergio Amadeu da. A noção de exclusão digital diante das exigências de uma cibercidadania. In: HETKOWSKI, Tânia Maria (Org.). Políticas públicas \& inclusão digital. Salvador: EDUFBA, 2008.

TEIXEIRA, Adriano Canabarro. Inclusão digital: novas perspectivas para a informática educativa. Ijuí: Editora Unijuí, 2010.

TEIXEIRA, Adriano Canabarro. Internet e democratização do conhecimento: repensando o processo de exclusão social. Dissertação (Mestrado) - Universidade de Passo Fundo, 2001.

TEIXEIRA, Adriano Canabarro; PEREIRA, Ana Maria de Oliveira; TRENTIN, Marco Antônio Sandini (Org.). Inclusão digital: tecnologias e metodologias. Passo Fundo: UPF Editora, 2013.

UNIÃO Internacional de Telecomunicações (UIT). Measuring the information society. Geneva, 2013. 